of an existing community-based Total Worker Health (TWH) intervention - Health Links plus senior-level TWH leadership training - which aims to build small business capacity around health, safety and wellbeing policies and programs as well as strengthen organisational climates.

Methods We are recruiting small businesses with fewer than 500 employees in a variety of high and low hazard industries in Colorado USA. Upon enrolment, businesses are randomised into one of two doses:

- Health Links plus senior-level TWH leadership training and

- Health Links.

Annual business- and employee-level assessments are collected.

Results Data collection began in April 2017 and we will have baseline data to share from about 100 businesses and 3500 employees. We will present a cross-sectional assessment of (1) organizational-level adoption of TWH policies and programs (2) organisational safety and health climates, and (3) workerlevel health and safety outcomes.

Preliminary data from businesses enrolled in Health Links prior to the start of the study $(n=145)$ indicates variation in level of policies and programs by business. Thus, we hypothesise that small businesses that have more TWH policies and programs have (1) more positive organisational safety and health climates, and (2) safer and healthier workers.

Discussion Little is known about small business capacity for delivering health, safety and wellbeing. Even less is known about how TWH interventions impact employee safety, health and well-being in small enterprises. This information is needed to understand how to creategeneralizable TWH interventions that can have a broad public health impact.

\section{VALUE ON INVESTMENT FOR SMALL BUSINESS SAFETY, HEALTH AND WELLBEING}

${ }^{1}$ Natalie Schwatka*, 'Lee Newman, ${ }^{2}$ Claire Brockbank, 'Liliana Tenney, ${ }^{1}$ Miranda Dally, ${ }^{3}$ Kim Jinnett, ${ }^{4}$ Adam Atherly, ${ }^{5}$ Ron Goetzel, ${ }^{6}$ James McMillen, 'David Weitzenkamp, ${ }^{1}$ Derek Smith, 'Erin Shore. ${ }^{1}$ University of Colorado Denver, Colorado School of Public Health, Centre for Health, Work, and Environment, Aurora, USA; ${ }^{2}$ Segue Consulting, Denver, USA; ${ }^{3}$ Integrated Benefits Institute and Centre for Workforce Health and Performance, San Francisco, USA; ${ }^{4}$ University of Colorado Denver, Colorado School of Public Health, Department of Health Systems, Management, and Policy, Aurora, USA; ${ }^{5}$ Johns Hopkins University Bloomberg School of Public Health, Institute for Health and Productivity Studies, and IBM Watson Health, Bethesda, USA; ${ }^{6}$ Pinnacol Assurance, Denver, USA

10.1136/oemed-2018-ICOHabstracts. 1398

Introduction Health promotion programs may succeed in midto large-size companies, but what can be done to reach the small enterprises where the majority of people work? Furthermore, how successful can these efforts be and what is the value of investing in small business employee health? This presentation will examine the nexus of workers' compensation (WC), health promotion, productivity and small businesses.

Methods Three-hundred and fourteen businesses and 16926 of their employees participated in a multi-year worksite wellness program offered by a WC insurer in the United States from 2010-2014. Yearly self-report health risk assessment data and WC claims data were collected. In a series of studies using logistic and generalised linear models, we examined the relationship between employee health, safety and productivity. Additionally, using data from employees who participated in the program for $2+$ years $(n=5,766)$, we examined the change in health during the WWP.

Results A greater number of small businesses ( $<500$ employees) participated in the WWP than large businesses (500 +employees). Additionally, small businesses had higher employee participation rates than large businesses.

WC claims were best predicted by the occurrence of a previous WC claim and poor behavioural health (e.g., depression). Productivity at work was best predicted by previous WC claim, increasing numbers of chronic health conditions, and work task difficulty.

Small businesses gained the most from the WC insurerdriven WWP, compared to large businesses. Small businesses (<500 employees) saw improvements in job health culture, stress, depression, overall health rating, smoking, nutrition, and exercise from baseline to 1 st and 2nd follow-up.

Discussion Our results demonstrate the value of investing in employee health generally and the value of doing so through local, intermediary organisations. Employers who control jobsite safety hazards and promote employee health can observe gains in productivity and reductions in injury.

\section{HEALTH INEQUALITIES, WORK AND ACCESS TO SOCIAL SECURITY OF INFORMAL WORKERS IN LATIN AMERICA, AFRICA AND ASIA}

O Solar*, P Bernales, MJ Gonzalez, A Riesco, A Vives, V Alamos. Work, Employment and Health Inequities Faculty of Social Science of Latinamerica (FLACSO), Santiago Chile

\subsection{6/oemed-2018-ICOHabstracts.1399}

Introduction Around the world exist the expansion of the informal economy and traditionally people -working in the informal economy (WIE) do not have access to the established state-run healthcare systems. Understanding the barriers that explain the low participation of people-working informal economy in health systems and social security systems, providing social protection and eliminate obstacles to accessing care, should be viewed by governments as a strategy to improve the health of these workers.

Methods Develop baseline of information on the health and occupational health of informal workers and their access to health and social security systems in 6 countries of Africa, 6 of Asia and 12 countries of Latin America. The methodology included Case Studies were oriented to analyse access to health and social security, their employment and working conditions and their relationship to the characteristics of the countries' economic structure. The Qualitative Studies Component collected the primary information based on the informal workers' perception The Core Indicators component aimed to build indicators on several domains and subdomains of informal work and health that are relevant, robust and comparable between countries, as well as to identify information gaps, based on the analysis of different country surveys.

Result People -WIE are women and men from different age groups - higher rate of work among eldest and youngest groups - and educational backgrounds levels, living in urban and rural areas; present in different industrial sectors -; strong 
positive association between a country's proportion of informal jobs and its statistics on productive years of life lost and disability-adjusted life years (DALYs); high burden of disease that affects informal workers.

Discussion The lack of evidence on this subject has been detrimental to the development of sound policies addressing access to health by people-WIE and their families.

\section{WORKPLACE DESIGN AND WELLNESS PROGRAMME AMONG ARTISANS (INFORMAL WORKERS) IN 'MECHANIC VILLAGE' (AUTOMOBILE REPAIR GARAGES) IN ABEOKUTA, NIGERIA}

${ }^{1}$ Shamusideen Kadiri, ${ }^{2}$ Dakwak Selle. ${ }^{1}$ Principal Consultant, Zub Chord Tech Ventures, Lagos Nigeria; ${ }^{2}$ Deputy Director, Industrial Training Fund, Jos, Nigeria

\subsection{6/oemed-2018-ICOHabstracts. 1400}

Introduction The International Labour Organisation (ILO) showed that informal sector workers in developing countries are exposed to poor working environments, low safety and health standards. Such exposure impairs their health and productivity as well as the general well-being and quality.

Methods The study used the approach in Work Improvement in Small Enterprises (WISE) by ILO and WHO model of Healthy workplace in providing solution to the identified problems of poor working condition and awareness on healthy workplace.

One hundred and thirteen (113) Participants were involved in the study consisting (44) auto mechanic artisans, (27) auto electricians artisans, (7) Motor Vehicle tire repairs artisans, (15) automobile body repair artisans, (8) battery chargers, and (12) food vendors.

The observation of work practice improvement involved using a checklist based on the Work Improvement Small Enterprises (WISE) and the WHO model of Healthy workplace. The checklist consists of the 27 practice improvement sections and including improvements in the: materials storage and handling, work-station design, working conditions, waste disposal, welfare facilities and health promotion. Onsite training was carried by the researchers and stakeholders in Occupational Health and Safety (OHS) within the study area.

Result During the participatory learning activities that were presented in this study, the informal-sector workers engaged in the group discussions and identified the OHS problems in their own sector. They subsequently attempted and accurately understood work related safety issues, and collectively proposed and implemented safety measures. Their awareness on workplace health promotion increase and they were able to identify measures to prevent ill health either at work or at home.

Discussion Our findings suggest that positive attitudes toward promoting safe working conditions and practices can be fostered among the informal-sector workers by raising their knowledge and skills regarding issues related to $\mathrm{OSH}$ through a capacity building process.

\section{DEVELOPING FACILITATOR TRAINING TOOLKITS BY INTERCOUNTRY NETWORKING FOR ADJUSTING PARTICIPATORY STEPS OF PREVENTING OVERWORKING TO LOCAL SITUATIONS}

${ }^{1} \mathrm{~K}$ Kogi, ${ }^{1} \mathrm{Y}$ Sano, ${ }^{2} \mathrm{~T}$ Nakao, ${ }^{3} \mathrm{~T}$ Yoshikawa, ${ }^{4} \mathrm{E}$ Yoshikawa, ${ }^{5} \mathrm{MS}$ Lee, ${ }^{6} \mathrm{JH}$ Roh, ${ }^{7} \mathrm{JS}$ Park, ${ }^{8} \mathrm{KH}$ Woo. ${ }^{1}$ Ohara Memorial Institute for Science of Labour, Japan; ${ }^{2}$ Tokyo Occupational Safety and Health Centre, Japan; ${ }^{3}$ National Institute of Occupational Safety and Health, Japan; ${ }^{4}$ Japanese Red Cross College of Nursing, Japan; ${ }^{5}$ Council of Group Occupational Health Services, Korea; ${ }^{6}$ Graduate School of Public Health, Yonsei University, Korea; ${ }^{7}$ Daegu Catholic University, Korea; ${ }^{8}$ Soonchunhyang Hospital, Korea

\subsection{6/oemed-2018-ICOHabstracts. 1401}

Introduction Awareness is growing of the need to effectively promote participatory workplace improvement in different work settings. Newly advancing networked collaboration among occupational health teams in Japan, Korea and other countries in Asia indicate the importance of relying on facilitator training in adjusting participatory programmes to each local situation. It is useful to elucidate effective ways to train facilitators acting in the local context of implementing readily feasible improvements preventing overworking in varied local situations.

Methods Commonly effective procedures for training facilitators acting in participatory action-oriented programmes for preventing overworked situations were reviewed. How the intercountry networking of these experiences contributed to the development of locally adjusted training methods was examined. Attention was paid to simplified procedures and action checklists in training facilitators supporting workers in conducting practical improvements in the local context.

Results The intercountry networking led to annual workshops that confirmed the efficacy of simplified procedures for participatory programmes aimed at locally feasible improvements. These simple procedures proved useful for achieving multifaceted improvements in work methods, physical environment and work organisation. The collaboration of network partners verified the suitability of simple procedures addressing multiple aspects of work. Reflecting this progress, the network partners developed a similarly simple process of facilitator training. The use of a locally adjusted participatory toolkit comprising illustrated good practices and an action checklist of low-cost ideas was consistent. Facilitator training utilising this toolkit in guiding workers thus proved effective in different occupations. Conclusions Inter-country collaboration in joint development of facilitator training methods in participatory workplace improvement programmes for preventing overworking proved effective. Simplified training procedures were confirmed useful when they emphasised local good practices and facilitation by means of a locally adjusted toolkit. It is recommended to make full use of interactive networking incorporating these training features. 